\title{
Erisipela suína: relato de caso no município de Cachoeiras de Macacu-RJ*
}

\section{Swine erysipelas: case report in the city of Cachoeiras de Macacu-RJ}

\author{
Renato Luiz Silveira, ${ }^{* *}$ Ana Claudia de Menezes Cruz, ${ }^{* * *}$ Fabiana Batalha Knackfuss, ${ }^{* \star *}$ Ingrid Lyrio Figueira Rodrigues ${ }^{\star * * \star *}$
}

\begin{abstract}
Resumo
Na suinocultura perdas econômicas ainda são elevadas devido aos baixos padrões de qualidade e sanidade dos animais. Dentre as afecções que afetam a produção, a erisipela é uma doença considerada importante em função dos prejuízos econômicos que causa, e pela questão de saúde pública visto ser uma zoonose. Ela é uma enfermidade do tipo hemorrágica comumente causada pela bactéria ubíqua Erysipelotrix rhusiopathiae. O objetivo deste trabalho foi relatar um caso desta afecção em uma matriz da raça Large White, de dois anos de idade, recém desmamada, não vacinada, de uma pequena granja de ciclo completo no munícipio de Cachoeiras de Macacu, estado do Rio de Janeiro. Ela amanheceu prostrada, com dificuldade de locomoção, sem febre e com manchas avermelhadas sobre toda a superfície corporal. As lesões cutâneas, ligeiramente elevadas, apresentavam um formato losangular (diamante) característico e sugestivo de Erisipela. Após a identificação do problema, o animal foi isolado e tratado. $O$ tratamento iniciou-se na manhã do mesmo dia, observando-se a regressão da maioria das lesões à tarde e na manhã seguinte. A suspeita clínica foi confirmada através do diagnóstico terapêutico, sendo a associação de penicilina e estreptomicina eficiente no tratamento.
\end{abstract}

Pavalavras-chave: Erisipelothrix spp., suíno, ruiva dos porcos.

\begin{abstract}
In swine industry, economic losses are still high due to low standards of quality and health of animals. Among the diseases that affect production, erysipelas is a disease considered important due to the economic losses it causes, and because of the public health issue as it is a zoonosis. It is a hemorrhagic type disease commonly caused by the ubiquitous bacteria Erysipelotrix rhusiopathiae. The aim of this study was to report a case of this condition in a Large White breed sow, two years old, recently weaned, not vaccinated, from a small pig farm (farrow to finish operation) in the municipality of Cachoeiras de Macacu, state of Rio de Janeiro. The sow was prostrate and with limited mobility, without fever and with reddish spots on the entire body surface. The cutaneous lesions were elevated, with a characteristic diamond shape suggestive of erysipelas. After identifying the problem, the animal was isolated and treated. The treatment started in the morning of the same day, observing the regression of most lesions in the afternoon and the following morning. The clinical diagnosis was confirmed through therapeutic diagnosis, and the association of penicillin and streptomycin was efficient in the treatment.
\end{abstract}

Keywords: Erysipelothrix spp., swine, swine rotlauf bacillus.

\section{Introdução}

Na suinocultura, perdas econômicas ainda são elevadas devido aos baixos padrões de qualidade e sanidade dos animais. Dentre as afecções que afetam a produção, a erisipela é uma doença considerada importante em função dos prejuízos econômicos que causa, e pela questão de saúde pública visto ser uma zoonose (CARDOSO, 2009; PIVA FILHO et al., 2011; CHAGAS et al., 2019). A doença manifesta-se de forma semelhante em animais e no homem. As lesões na pele e a poliartrite são as formas típicas nos animais e o erisipelóide, uma infecção cutânea local e artrites digitais no homem (WANG et al., 2010).
A erisipela é uma enfermidade do tipo hemorrágica comumente causada pela bactéria ubíqua Erysipelotrix rhusiopathiae. Apresenta distribuição mundial, sendo o suíno e o peru os animais mais afetados, seguidos por outras aves, pequenos ruminantes e peixes (MUSEWA et al., 2018), tendo nos javalis uma fonte potencial de infecção para outros animais (SHIMOJI et al., 2019). O agente é imóvel, Gram-positivo, em forma de bastonete, podendo apresentar-se em formas variadas (OLIVEIRA e SOBESTIANSKY, 2007). É classificado genotipicamente em duas espécies, E. rhusiopathiae (sorotipos $1,2,4,5,6,8,9,11,12,15,16,17,19,21$ e N) e E. tonsilarum $(3,7,10,14,20,22$ e 23) (OLIVEIRA, 2009).

${ }^{*}$ Recebido em 5 de maio de 2020 e aceito em 15 de junho de 2020.

**UFF - MMO/MCV - Niterói-RJ. Autor para correspondência: renatosilveira@id.uff.br

***UFF - NAL - Núcleo de Animais de Laboratório - Niterói-RJ.

****UNIGRANRIO - Escola de Ciências da Saúde - Faculdade de Veterinária - Duque de Caxias-RJ.

*****UFF - MZO - Niterói-RJ. 
A infecção acontece através da ingestão de alimentos ou água contaminada, ocorrendo a penetração pelas tonsilas ou tecido linfoide ao longo do tubo digestório, podendo também ocorrer através de ferimentos da pele. O período de incubação varia de um a sete dias. Acomete todas as idades, mas os mais jovens são mais resistentes em função da imunidade adquirida pelo colostro (OLIVEIRA e SOBESTIANSKY, 2007). Os animais mais sensíveis encontram-se entre seis e doze meses de idade (PERESTRELO VIEIRA et al., 2002).

Existem três formas da afecção: aguda, subaguda e crônica. A aguda se caracteriza pela doença septicêmica com manifestação súbita dos sinais clínicos como morte, abortamento, depressão, letargia, febre alta e dor articular com relutância na movimentação e lesões cutâneas. Na subaguda a forma clínica é menos severa. O animal não aparenta estar doente, a temperatura não é alta, não afeta o apetite e as lesões de pele acontecem em menor número ou são ausentes. A forma crônica é uma consequência das formas anteriores não tratadas. A artrite é um sinal clínico economicamente importante pois dificulta a movimentação dos animais e a consequente ingestão de alimentos (OPRIESSNIG e COUTINHO, 2019).

Sem as lesões características da pele, a erisipela pode ser confundida com outras doenças septicêmicas como a peste suína africana, a cólera suína e a salmonelose. Neste caso, o diagnóstico laboratorial que envolve isolamentos bacterianos e virais e testes sorológicos, auxiliam na diferenciação (WABACHA et al., 1998).

Segundo Barcellos et al. (2008), a maneira mais efetiva de manter rebanhos comerciais livres ou controlados em relação a agentes de enfermidades de impacto econômico e evitar efeitos negativos à produtividade e/ou saúde pública (zoonoses) é através da utilização de programas de biossegurança. Reis e Reis (2014) observam que o custo de sua implantação é mínimo quando comparado às perdas potenciais por doença.

\section{Relato do caso}

O caso aconteceu no munícipio de Cachoeiras de Macacu, estado do Rio de Janeiro, em uma pequena granja de ciclo completo e que apresentava algumas deficiências na questão de biosseguridade.

O animal, fêmea de dois anos de idade, recém desmamada, da raça Large White, não vacinada, amanheceu prostrada, com dificuldade de locomoção, sem febre e com manchas avermelhadas sobre toda a superfície corporal segundo informação do funcionário. As lesões cutâneas, ligeiramente elevadas, apresentavam um formato losangular (diamante) característico e sugestivo de Erisipela.

Uma vez identificado o problema, o animal foi isolado e tratado. A baia onde se encontrava foi imediatamente limpa e desinfetada. O tratamento consistiu na aplicação intramuscular de uma associação entre penicilina, estreptomicina e piroxicam durante cinco dias (Agrosil 5 Mega ${ }^{\circledR}$, Vansil Saúde Animal, 187.500 UI de Benzilpenicilina Procaína + 62.500 UI de Benzilpenicilina Potássica $+100 \mathrm{mg}$ de Estreptomicina base), $1 \mathrm{ml}$ para cada $10 \mathrm{Kg}$ de peso, sendo já observada a regressão da maioria das lesões na tarde do mesmo dia e na manhã seguinte.

\section{Discussão}

Neste relato foram observadas lesões na pele (Figura 1A a 1E), com formato de diamante, ligeiramente elevadas, ao redor do nariz, orelhas, pescoço, abdômen e coxa. Segundo Opriessnig e Coutinho (2019), nestes locais e com estas características, as lesões são consideradas patognomônicas para a doença. Não houve alteração de temperatura do animal o que, segundo Oliveira e Sobestiansky (2007), mesmo com lesões típicas da enfermidade, pode acontecer.

Economicamente, a artrite é a mais importante manifestação clínica pois prejudica o crescimento dos animais, aumentando a condenação de carcaças no abate (ALBERTON et al., 2003b; GERBER et al., 2018). Segundo Alberton et al. (2003a) um dos principais agentes causadores de artrite infecciosa na espécie suína é o Erysipelothrix rhusiopathiae.

Neste relato, alguns fatores mostraram um possível envolvimento articular do E. rhusiopathiae. O primeiro foi o fato do animal ser encontrado prostrado e imóvel (Figura 1A). Chamou a atenção o fato do seu cocho apresentar quase toda a ração colocada na tarde anterior. O segundo fator foi a sua relutância e vocalização no momento do transporte para a baia de isolamento. O terceiro foi que no fim do dia, após o início do tratamento, o animal já se movimentava e se alimentava.

Oliveira e Sobestiansky (2007) indicam que é muito difícil a erradicação do agente em função de sua boa capacidade de adaptação ao ambiente, além de poder ser excretado por animais portadores sadios.

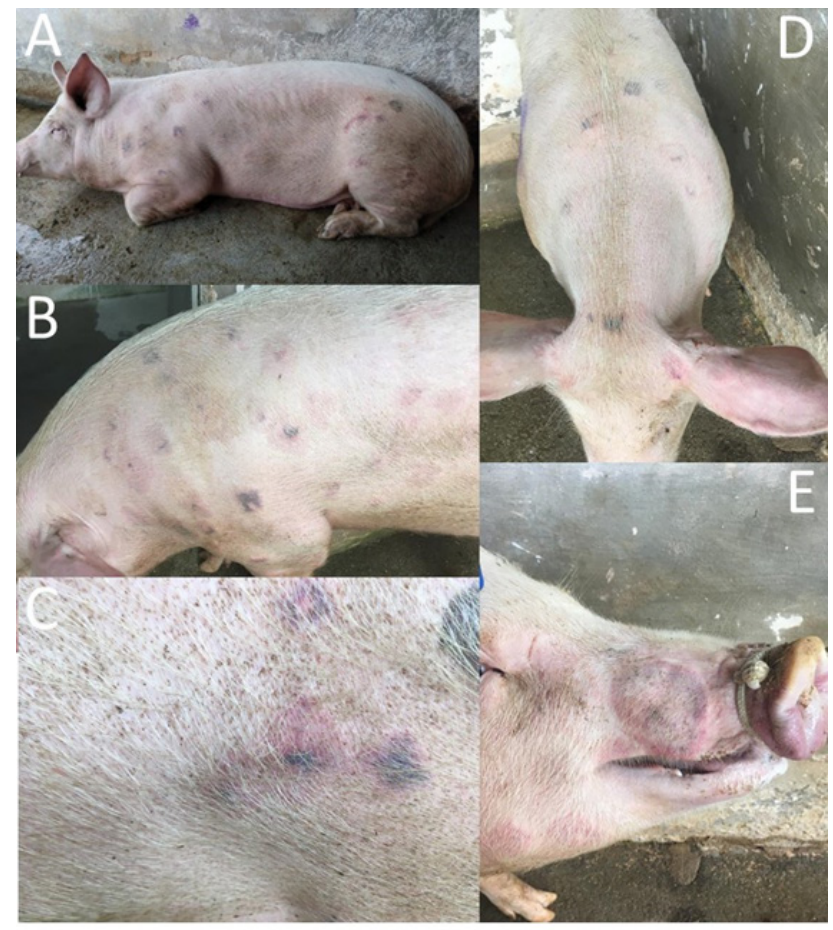

Figura 1: Fotomacrografia. Espécie suína. A/B/C/D. Lesões cutâneas em regiões variadas do corpo, de coloração variada, com formato de diamante, sugestivas de Erisipelose. E. Lesão cutânea elevada na região lateral do lábio superior direito.

Cachoeiras de Macacu-RJ, 2020. Fonte: Arquivo pessoal. 
Em termo práticos, o objetivo de toda granja é ser livre do maior número possível de doenças, sendo o principal fator de eficiência e rentabilidade. Assim, a prevenção da entrada e controle das doenças existentes será decisivo entre lucro e prejuízo (REIS e REIS, 2014).

Neste relato, após a identificação do problema e do isolamento do animal, iniciou-se imediatamente o tratamento. Fato semelhante aconteceu com Leitão et al. (2011), que relataram que não houve diagnóstico laboratorial devido à urgência do caso e deficiência diagnóstica na região. Observaram também

\section{Referencias}

ALBERTON, G.C.; BANDARRA, E.P.; PIFFER, I.A.; MORES, M.A.Z.; PEREIRA, M.A.C.; YAMAMOTO, M.T. Exame anatomopatológico, microbiológico, citológico e físico-químico das articulações de suínos artríticos no matadouro. Archives of Veterinary Science. v.8, n.1, p.81-91, 2003a.

ALBERTON, G.C.; BARIONI JÚNIOR, W.; PIFFER, I.A.; BANDARRA, E.P. Diagnóstico diferencial entre artrite infecciosa e não infecciosa em suínos no matadouro: Critérios para julgamento das carcaças afetadas. Comunicado Técnico, 330. EMBRAPA. CNPSA. p.1-6, 2003b.

BARCELLOS, D.E.S.N.; MORES, T.J.; SANTI, M.; GHELLER, N.B. Avanços em programas de biosseguridade para a suinocultura. Acta Scientiae Veterinariae. n.36 (Supl 1): a33-a46, 2008.

CARDOSO, M. O que representam os suínos na transmissão de zoonoses para humanos? Acta Scientiae Veterinariae. n.37 (Supl 1): a81-a89, 2009.

CHAGAS, S.R.; DALL'AGNOL, M.; PESSOA, A.V.C.; RAMISVIDAL, M.G.; PASCOAL, L.M. Aspectos epidemiológicos atuais da parvovirose, erisipela e leptospirose: seus impactos na suinocultura e saúde pública. PUBVET. v.13, n.8, a397, p.1-15, Ago, 2019.

GERBER, P.F.; MACLEOD, A.; OPRIESSNIG, T. Erysipelothrix rhusiopathiae serotype 15 associated with recurring pig erysipelas outbreaks. Veterinary Record. v.182, n.22, p.1-4, 2018.

LEITÃO, D.F.G.M.; SILVEIRA, R.L.; PEREIRA, P.F.; CRUZ, A.C.M.; CARVALHO, E.C.Q. Relato de caso de erisipela suína no município de Silva Jardim, RJ. Jornal Brasileiro de Ciência Animal. n.4, v.8, p.292-301, 2011.

MUSEWA, A.; ROESEL, K.; GRACE, D.; DIONE, M.; ERUME, J. Detection of Erysipelothrix rhusiopathiae in naturally infected pigs in Kamuli District, Uganda. Revue D'Élevage et de Médecine Vétérinaire des Pays Tropicaux. n.71, v.1-2, p.97-101, 2018.

OLIVEIRA, S.J. Erisipela suína: sempre importante à suinocultura. Acta Scientiae Veterinariae. n.37 (Supl 1): a97-a104, 2009. que o tratamento recomendado permitiu um diagnóstico terapêutico.

Por fim, cabe observar a condição epidemiológica desta afecção, quanto ao seu caráter emergente ou negligenciado.

\section{Conclusão}

A suspeita clínica foi confirmada através do diagnóstico terapêutico, sendo a associação de penicilina e estreptomicina eficiente no tratamento.

OLIVEIRA, S.J.; SOBESTIANSKY, J. Erisipela. In: SOBESTIANSKY, J.; BARCELLOS, D. Doenças dos suínos. $2^{\text {a }}$ ed. Goiânia. Cânone Editorial. 2007, p.168-172.

OPRIESSNIG, T.; COUTINHO, T.A. Erysipelas. In: ZIMMERMAN, J.J.; KARRIKER, L.A.; RAMIREZ, A.; SCHWARTZ, K.J.; STEVENSON, G.W.; ZHANG, J. Diseases of swine. Hoboken: Wiley Blackwell, 2019, p.835-843.

PERESTRELO VIEIRA, R.; PERESTRELO VIEIRA, H.; SOBESTIANSKY, J.; GOURREAU, J.M. Dermatologia suína. In: PERESTRELO VIEIRA, R.; VANNIER, P.; SILVEIRA, D.; SOBESTIANSKY, J.; PERESTRELO VIEIRA, H.; GOURREAU, J.M. Manual de práticas veterinárias: A doença de Aujeszky, Técnica de necropsia em suínos, Vademecum da febre aftosa, Dermatologia suína. Lisboa. Fundação Calouste Gulbenkian, 2002, p.317-364.

PIVA FILHO, G.L.; LARA, L.J.; PREZOTTO, C.F.; SOARES, B.A.; PALOMINO, B.M.; AMBRÓSIO, N.A.; GIBSON, K.; BARRIOS, P.R.; PECONICK, A.P.; PEREIRA, S.M. Inspeção e julgamento das carcaças acometidas com erisipela suina em frigorifico. In: XXXVIII Congresso Brasileiro de Medicina Veterinária, 2011, Florianópolis-SC. Anais. XXXVIII CONBRAVET, 2011.

REIS, R.; REIS, A. Fundamentos teóricos e aplicação prática da biosseguridade na produção de suínos. In: ABCS. Produção de suínos: Teoria e prática. Brasília. Gráfica Qualitá. 2014, p.847854.

SHIMOJI, Y.; OSAKI, M.; OGAWA, Y.; SHIRAIWA, K.; NISHIKAWA, S.; EGUCHI, M.; YAMAMOTO, T.; TSUTSUI, T. Javalis: Uma fonte potencial de infecção por Erysipelothrix rhusiopathiae no Japão. Microbiology and Immunology. n.63, v.11, p.465-468, 2019.

WABACHA, J.K.; GITAUA, G.K.; NDUHIUA, J.M.; THAIYAA, A.G.; MBITHIA, P.M.F.; MUNYUA, S.J.M. An outbreak of urticarial form of swine erysipelas in a medium-scale piggery in Kiambu District, Kenya. South African Veterinary Association, v.69, n.2, p.61-63, 1998.

WANG, Q.; CHANG, B.J.; RILEY, T.V. Erysipelothrix rhusiopathiae. Veterinary Microbiology. n.140, v.3-4, p.405-417, 2010. 